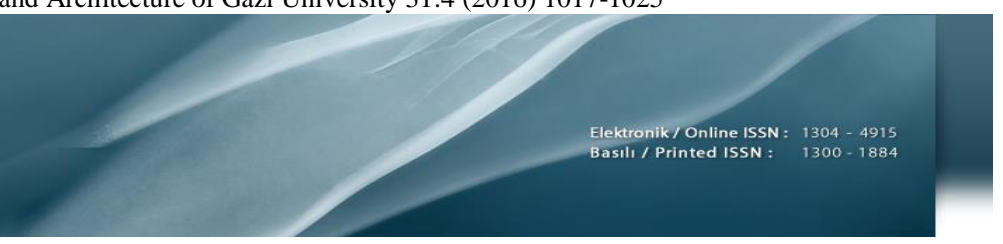

\title{
Katı kümeleme ve yeni bir geçiş fonksiyonuyla uzman karışımlarında sınıflandırma
}

Faruk Bulut $^{1 *}$, M. Fatih Amasyal1 ${ }^{2}$

${ }^{1}$ Katip Çelebi Üniversitesi, Mühendislik-Mimarlık Fakültesi, Bilgisayar Mühendisliği Bölümü, Çiğli, İzmir

${ }^{2}$ Yıldız Teknik Üniversitesi, Elektrik-Elektronik Fakültesi, Bilgisayar Mühendisliği Bölümü, Davutpaşa, İstanbul

Ö N E Ç I K A N L A R

- $\quad$ Katı kümeleme ile yeni bir Uzman Karışımı modeli

- Yeni bir geçiş fonksiyonun tasarlanması

- Uzman Karışımları ile yüksek sınıflandırma performansı

Makale Bilgileri

Geliş: 10.10 .2015

Kabul: 28.03.2016

DOI:

10.17341/gazimmfd.278457

Anahtar Kelimeler:

Uzman karışımları, geçiş fonksiyonu, siniflandirma

\section{ÖZET}

Uzman Karışımları, Kolektif Öğrenme metotlarından biridir ve sınıflandırma başarısını artırmak için yaygın olarak kullanılmaktadır. Bu algoritmada, veri seti yumuşak kümeleme ile alt bölümlere ayrılır. Her bir bölüm için ayrı bir sınıflandırıcı uzman oluşturulur ve o bölümdeki örneklerle eğitilir. Belirlenen bir geçiş fonksiyonu ile de uzmanların kararları birleştirilerek sınıflandırma işlemi yapılır. Bu çalışmada veri seti, literatürde önerilen yumuşak kümeleme yerine katı kümeleme yöntemiyle alt veri setlerine bölünmüştür ve her bir alt veri seti için ayrı bir sınıflandırıcı atanmıştır. Uzmanların kararları da önerilen yeni bir geçiş fonksiyonu ile birleştirilmiştir. Bu geçiş fonksiyonu sayesinde, her hangi bir test noktası için tüm uzmanların o test noktasına olan uzaklıklarına bağlı olarak verdikleri kararlar ağırlıklandırılarak birleştirilir ve ortak komite kararı hesaplanmıştır. Bir grup veri seti üzerinde yapılan denemelerde, karar ağaçları ve $k$ en yakın komşuluk algoritması gibi tekil sınıflandırıcılara göre uzman karışımlarının daha başarılı sonuçlar verdiği gözlemlenmiştir.

\section{Classification in mixture of experts using hard clustering and a new gate function}

\section{H I G H L I G H T S}

- A new model with hard clustering

- A new gate function design

- High classification performance via Mixture of Experts

Article Info

Received: 10.10 .2015

Accepted: 28.03.2016

DOI: 10.17341/gazimmfd.278457

Keywords: Mixture of experts, gate function, classification

\section{ABSTRACT}

As one of the ensemble methods, Mixture of Experts is used to gain higher prediction performance in classification area. In this technique, a dataset is divided into regions by soft clustering. An expert for each region is assigned and trained with the samples of the corresponding region. In this study, a dataset is divided into regions by a hard clustering method and a decision tree classifier is constructed for each region as an expert. Each expert has their individual decision for a test point. The class prediction for the test point is performed by the proposed gate function which aggregates all the decisions of experts. In calculations of the final decision via the gate function, each expert has different weights according to its distance to the test point. In the experiments on a group of benchmark datasets, better performance has been obtained with the new gate function. This new method gives better results than base classifiers such as decision trees and $\mathrm{k}$ Nearest Neighbors.

\footnotetext{
* Sorumlu Yazar/Corresponding author: faruk.bulut@ikc.edu.tr / Tel: +90 2323293535
} 


\section{GİRIŞ̧ (INTRODUCTION)}

RBF (Radial Basis Functions) metodunun geliştirilmiş bir versiyonu olan UK (Uzman Karışımları) ilk olarak Jacobs ve Jordan tarafindan önerilmiştir [1]. UK, kolektif öğrenme (Ensemble Learning) yöntemlerinden biridir. UK'da amaç, veri setini böl-yönet mantığıyla daha az karmaşık bir yapıya indirgeyerek sinıflandırma performansını artırmaktır. UK ile veri seti en uygun şekilde alt kümelere bölünür ve her bir alt küme için bir uzman atanarak o bölgedeki örneklerle eğitilir. Amaç her bir alt bölgenin bir veri seti gibi düşünülüp o bölge için en uygun sınıflandırıcının eğitilmesidir ve toplam sinıflandırma performansının artırılmasıdır. Bir veri setinin alt bölgeleri birbirinden farklı yapılar içeriyor olabilir. Bu farklılıklar, örnek sayısından, sınıf etiketi sayısından, verilerin tipinden, yoğun veya seyrek oluşundan ve değişik istatistiksel ölçütlerden kaynaklanıyor olabilir. Bu farklılıklar sınıflandırma başarısı üzerinde olumlu ya da olumsuz etki oluşturabilir. Kümülatif sınıflandırma başarısını artırmak amacıyla tüm veri kümesi için tek bir model belirlemek yerine her bir alt bölge için farklı modeller tasarlamak ve bu modelleri uygun bir fonksiyonlar birleştirmek gerekebilir. UK algoritmasının başarısı iki temelde dayalıdır. Birincisi veri setinin alt bölümlerinin nasıl belirlendiği, diğeri ise test örneklerinin nasıl etiketlendiğidir. Literatürde veri setinin bölümlere ayrılma işlemi Beklenti Artırımı (Expectation Maximization, BA) algoritmasıyla ve etiketleme işleminin de BA yöntemine özgü bir geçiş fonksiyonu (Gating Function) ile yapıldığı anlatılmaktadır [2]. Bilindiği üzere BA yöntemi, yumuşak bir kümele (soft clustering) yapmaktadır. Diğger bir deyişle veri setindeki her bir örnek belirli bir oranda birden fazla kümeye ait olabilir. UK yönteminde bir test örneğinin etiketlenmesi işlemi ait olduğu her bir kümenin uzmanları tarafindan verilen kararların birleştirilmesiyle yapılır. Verilen her bir karar ilgili test örneğinin o kümeye ait olma oranıyla doğru orantılı olacak şekilde ağırlıklandırılır. Kararların bir fonksiyon ile birleştirilmesiyle de komite kararı bulunmuş olur. UK alanında son 20 yıl içerisinde teorik çalışmalar yapılmış, farklı yaklaşımlar sunulmuştur. Bir sınıflandırma modeli olarak UK algoritması, hazır ve ortak kullanıma açık veri setlerinin yanı sıra özel bir amaç için hazırlanmış olan veri kümelerine de uygulanabilmektedir. UK modeli görüntü işleme, yüz tanıma, yüzden cinsiyet ve etnik özellikleri çıkarma, el yazısı tanıma, robot yol bulma, sağlık ve tıp bilişimi, protein etkileşim tahmini, ses tanıma, ses gruplama, 3B nesne tanıma, sinyal işleme, hava tahmin ve raporlama gibi birçok alana uygulanmış ve diğer klasik yöntemlere göre daha başarılı sonuçlar elde edilmiştir. Ayrıca geliştirilmiş değişik stratejilerle UK'nın sınıflandırma başarısı artırılmaya çalışılmıștır. Seniha, Wilson ve Gader 2014 yılında yayınladıkları literatür taramasında [3], UK alanında son 20 yil içerisinde yapılmış çalışmaları incelenmiştir. Çalışmalarında UK'nın varyasyonlu öğrenme metoduna (Variational learning of $M E)$, hiyerarşik UK modellerine, en uygun sayıdaki uzmanın tespit edilmesine, UK ile geliştirilmiş sinıflandirma ve regresyon modellerine, Bayesin UK modeline, UK'nın istatistiksel modellerine, yıllar içerisindeki değişimlerine ve bu alanda yapılan pratik uygulamalara yer verilmiştir. Bir veri setinde sınıf türlerine ait veri dağılımları dengesiz ve asimetrik olabilir. Sınıf türlerine bakılmaksızın örnekler veri uzayında kuyruk yapısında veya kıvrımlı bir şekilde bulunabilir. Genel olarak tüm veriler gauss dağılımına uygun da olmayabilir. Ayrıca belirli özniteliklere ait veriler zamana, mekâna, sıcaklığa ve bazı durumlara bağlı olarak değişiklik gösterebilir. Bir veri seti hem devingen hem de durağan veriler içerebilir. $\mathrm{Bu}$ gibi durumlarda hem tekil sinıflandırıciların [4] hem de UK modellerinin [5] beklenen düzeyde performans gösteremeyeceği literatürde belirtilmiştir. Akben ve Alkan tarafindan yapılan çalışmada [4] öznitelikler arasındaki korelasyonun düşük olmasının sınıflandırma başarısını olumsuz etkilediği vurgulanmıştır. Chamroukhi tarafından yapılan çalışmada [5] ise NonNormal Mixture of Experts (NNMoE) modeli öne sürülmüştür. Dengesiz (skewed) ve kuyruklu (tailed) veri setleri oluşturmak için ürettikleri sentetik veri setlerinde klasik UK modeline göre regresyon, sinıflandırma ve kümeleme işlemlerinde yüksek düzeyde başarı oranı elde edilmiștir. Normal bir dağılıma sahip veri setinde gürültülü noktalara (noise) karşı normal bir UK modeli hassas bir yapıya sahiptir. Nguyen ve McLachlan tarafından yapılan bir çalışmada ise gürültü eklenmiş veri setlerine karşı gürbüz (robust) bir yapıya sahip Laplace mixture of linear experts (LMoLE) modelini öne sürmüşlerdir [6]. Lineer bir regresyon modeli ile sinıflandırma yapan LMoLE algoritmasında gürültülü verilere karşı başarılı sonuçlar elde edilmiştir.

$\mathrm{Bu}$ çalışmada, her bir alt bölgeyi ayrı bir veri seti gibi düşünerek olası bazı olumsuz etkilerin en aza indirilmesi amaçlanmıştır. $\mathrm{Bu}$ sayede genel sınıflandırma başarısının artırılacağı düşünülmüştür. Bu amaçla tüm veri seti için tek bir öğrenici yerine, veri setinin her bir alt bölümü için ayrı ayrı öğreniciler inşa edilmiştir. Veri setinin alt bölümleri $k$ means yöntemiyle katı kümeleme (hard clustering) yapılarak belirlenmiştir. Normalde UK tasarımlarında, DBSCAN, OPTICS, Fuzzy-Means ve Beklenti Artırımı gibi yumuşak kümeleme yöntemleri kullanılarak gerçekleştirilmektedir. Homojen bir kolektif öğrenme yapısı oluşturmak için her bir alt bölüm ayrı bir Karar Ağacı (Decision Tree, KA) ile modellenmiştir. Bir test örneğinin etiketlenmesi için ise tüm uzmanların kararlarını birleştiren yeni bir geçiş fonksiyonu tasarlanmıştır. BA kümeleme algoritması her veri setinde çalışmamaktadır. BA kümeleme işlemi yaparken bazı durumlarda ill-conditioned diye ifade edilen kovaryans matrisinin oluşturulamama durumu ortaya çıkmaktadır. Birçok veri setinde karşılaşılabilecek bu durumda GMM (the Gaussian Mixture Model)'nin oluşturulmasında hata meydana gelmekte ve optimizasyon durmaktadır. $k$-means yöntemi, tüm veri setlerine rahatlıkla uygulanabileceği için BA ve GMM'ye göre oldukça avantajlıdır. Bu çalışmanın deneysel sonuçlar içeren ilk hali bir konferansta [7] sunulmuştur. Genişletilmiş ve geliştirilmiş bu çalışmada ise önerilen yöntem ile elde edilen başarılı sonuçlarının nedenlerine ve 
hangi durumlarda başarılı olduğunun belirlenmesine odaklanılmıştır. Çalışmamızın geriye kalan kısmında dört bölüm daha vardır. İkinci bölümde önerilen UK yöntemindeki geçiş fonksiyonunun yapısına, çalışma prensibine, uzman seçimine ve önerilen yöntemin zaman karmaşıklığı analizine yer verilmiştir. Üçüncü bölümde pratik uygulama ve deneysel sonuçlara; dördüncü bölümde ise değerlendirmelere ileri çalışmaların neler olabileceğine yer verilmiştir.

\section{UK İÇİN YENİ BİR YAKLAŞIM (A NEW APPROACH FOR MIXTURE OF EXPERTS)}

Her hangi bir test noktasının sınıflandırılması yumuşak kümelemeli klasik UK modelinde ait olduğu alt bölgenin uzmanının kararı ile yapılmaktadır. Fakat bu çalışmada bir test noktasının sinıflandırılması, katı kümeleme ile oluşturulan tüm bölgelere ait uzmanların verdikleri kararlarının birleştirilmesiyle yapılmaktadır. Birleştirme işleminde tasarlanan bir geçiş fonksiyonu kullanılmıştır.

\subsection{Yeni Bir UK Yaklaşımı ve Geçiş Fonksiyonu (A New MoE Approach and Gate Function)}

Kararların birleştirilmesi işlemi geçiş fonksiyonu adındaki bir mekanizma tarafindan yapılmaktadır [8]. Şekil 1'de görüldüğü üzere önerilen yaklaşımın yani UK'nın çalışma mantığ1 şu aşamalardan oluşur:

1. Veri seti $K$ adet alt kümeye ayrilır.

2. Ayrılan her bir alt küme için bir Uzman (Expert) atanır ve eğitilir.

3. Gelen $x$ test örneğinin etiketlenmesi için tüm alt uzmanlara danışılır ve kararları $\left(\mu_{i}\right)$ tek tek alınır.

4. Geçiş fonksiyonu ile tüm kararlar uzmanların test noktasına olan uzaklıklarına bağlı olarak ağırlıklandırılır $\left(g_{i} * \mu_{i}\right)$ ve birleştirilir.

5. Geçiş fonksiyonu test noktasının her bir sınıfa ait olma olasılı̆̆ı hesaplar.

6. Hesaplanan en yüksek orandaki sınıf türü ile test noktası etiketlenir (majority voting).

Çalışmamızda farklı bir uzman tasarımı ve buna bağlı olarak yeni bir geçiş fonksiyonu önerilmiştir. Şekil 1'de görüldüğü gibi geçiş fonksiyonu tarafindan, $x$ test noktasının etiketlenmesinde her bir uzmanın verdiği karar ağırlıklandırılır. Geçiş fonksiyonun tasarlanmasında yakında olan uzmanların etkisi fazla; uzakta olanların etkisinin az olması gerektiği düşüncesinden yola çıkılarak Shepard metodundan [9] yararlanılmıştır. Bir test noktasının sadece en yakında bulunan uzmana danışılarak sınıflandırılması durumunda hatalarının oluşması muhtemeldir. $\mathrm{Bu}$ test örneği bulunduğu alt kümenin karar sınırında ise ya da iki alt kümenin orta noktasında ise sınıflandırma işlemi başarısızlıkla sonuçlanabilir. $\mathrm{Bu}$ çalışmada bu soruna çözüm aranmış ve bahsedildiği üzere uzmanların uzaklıklarını temel alan yeni bir geçiş fonksiyonu tasarlanmıştır.

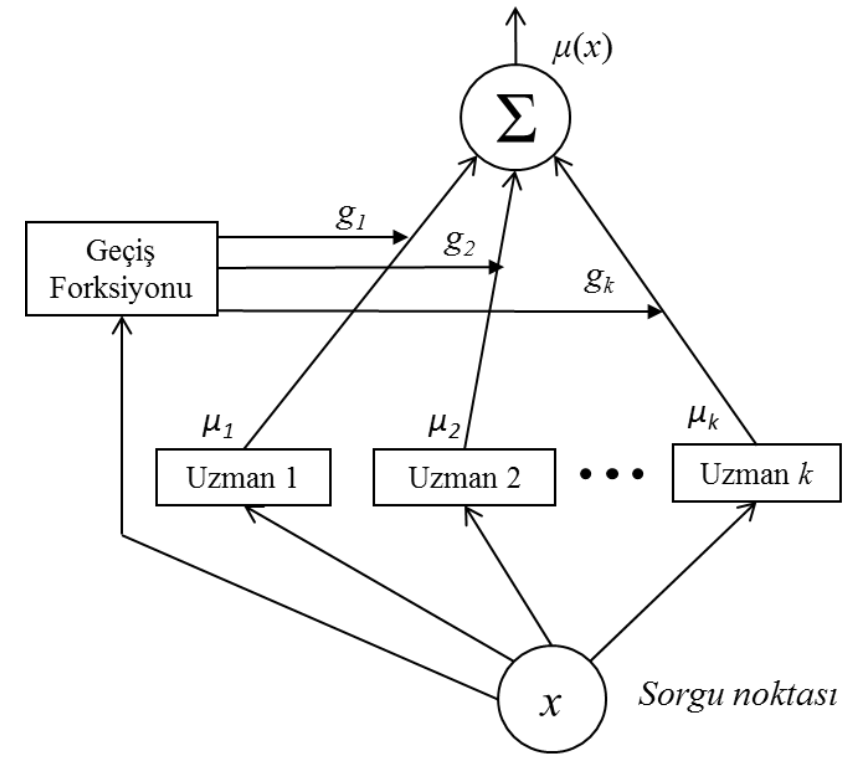

Şekil 1. UK'nın çalışma prensibi (Principals of ME)

Şekil 1'de görüldüğü üzere herhangi bir test örneği $x$ 'in sınıfinı bulan $\mu(x)$ fonksiyonunun genel yapışı Eş. 1'de görüldüğü gibidir.

$\mu(x)=\sum_{i=1}^{K} w_{i}(x) \mu_{i}(x)$

$\mu(x)$ fonksiyonun verdiği sınıflandırma kararı $\mu(x) \in[0,1]$, $i=1, \ldots, K ; j=1, \ldots, C$ şeklindedir. Eş. 1'de kullanılan $w_{i}, i$. uzmanın hesaplamadaki ağırlığıdır ve Eş. 2'de gösterildiği gibi hesaplanır.

$w_{i}=\frac{1}{d_{i}^{2}}=\frac{1}{d_{i}^{2}\left(x, E_{j}\right)}$

$x$ test noktası ve $E_{\mathrm{j}}$ arasındaki uzaklık Öklid uzaklık yöntemi Eş. 3 ile bulunmaktadır. $E_{j}, j$. uzmanın öğrendiği alt kümenin merkez noktasıdır. Merkez noktası bilindiği üzere küme içindeki eğitim örneklerinin aritmetik ortalaması ile bulunmaktadır ve ilgili uzmanı kolektif hesaplamada temsil etmektedir. A, veri uzayın özellik (boyut) sayısıdır ve herhangi bir noktanın özellikleri vektör olarak şu şekilde tanımlanmaktadır: $\left\langle a_{1}(x), a_{2}(x), a_{3}(x), \ldots a_{A}(x)\right\rangle$. Burada $a_{\mathrm{r}}(x), \quad x^{\prime}$ in $r$. özelliğini göstermektedir.

$d\left(x, E_{j}\right)=\sqrt{\sum_{i=1}^{A}\left(a_{i}(x)-a_{i}\left(E_{j}\right)\right)^{2}}$

Daha önce Tom Mitchell tarafından önerilen ve üzerinde çalışmalar yapılarak geliştirilen Distance-weighted-k-NN sınıflandırıcının [10] çalışma prensibi buraya uyarlanmış ve geçiş fonksiyonu olarak Eş. 4 geliştirilmiştir. $g_{i}, i$. uzmanın $x$ test noktası için hesaplamadaki ağırlığıdır.

$g_{i}=\frac{w_{i}}{\sum_{j=1}^{K} w_{j}}$ 
K'nın alt küme ve aynı zamanda uzman sayısını gösterdiği Eş. 5 her bir uzman için atanan yüzdelik ağırlıklar toplamı (G) 1'e eşittir. Görüldüğü üzere $x$ kaydının sınıfı belirlenirken uzaklığa bağlı olarak her bir KA'nın verdikleri kararlar ağırlıklandırılmıştır.

$G=\sum_{i=1}^{k} g_{i}=1$

$x$ 'in ait olabileceği sınıfların yüzdelik olarak en büyüğü ile etiketleme yapılabilmesi için sınıflandırma fonksiyonu Eş. 6'da, genişletilmiş hali ise Eş. 7'dir.

$\mu(x)=\operatorname{argmax}_{c \in C}\left(g_{i} \cdot \mu_{i}^{c}(x)\right)$

$\mu(x)=\operatorname{argmax}_{c \in C}\left(\frac{\sum_{i}^{K} w_{i} \cdot \mu_{i}^{c}(x)}{\sum_{j}^{K} w_{j}}\right)$

Burada $C$, veri setindeki tüm sonlu sınıf etiketleri kümesidir ve $\left\{c_{1}, c_{2}, c_{3}, \ldots, c_{s}\right\}$ elemanlarından oluşur. $\mu_{i}^{c}(x)$ fonksiyonu ise, $i$. uzmana göre $x^{\prime}$ in $c$ sinıfindan olma olasılığını hesaplamaktadır. $\mu: R \rightarrow C$ olan $\mu$ fonksiyonu tüm sinıf türleri için ayrı ayrı hesaplama yapıp maksimum argümanı sinıf etiketi olarak $x$ 'e atamaktadır.

\subsection{Temel Uzman seçimi (Base Expert Selection)}

UK'nın değişik pratik uygulamalarında farklı temel sınıflandırıcılar kullanılmıştır. Çok Katmanlı Algılayıcılar, Destek Vektör Makineleri, $k$ En Yakın Komşular yöntemi, Naive Bayes sınıflayıcısı ve lineer ayırıcılar gibi birçok öğrenici uzman olarak tercih edilmiştir. Bu çalışmada temel uzman seçimini, karar ağaçları ile yapılıştır. $k$-means ile oluşturulan $k$ tane alt veri setinin her biri ayrı bir veri seti gibi düşünülüp $k$ tane $\mathrm{KA}$ sinıflandırıcısı inşa edilmiştir. UK uygulamalarında KA kullanımı mantığı ilk olarak Jordan ve Jacobs tarafindan anlatılmıştır [11]. Bugüne dek UK yöntemleri üzerinde pek çok çalışma yapılmış ve farklılıkları gösterilmiştir. UK'nın günümüzde olduğu gibi Radial Basis fonksiyonlarıla kullanılmasını ilk olarak Lei $\mathrm{Xu}$ önermiştir [12]. Ayrıca KA'lar, kompakt ve sınıflandırmayı kolaylaştırıcı özelliğinden ötürü Radial Basis fonksiyon ağlarında TB-RBF (Decision Tree based Radial Basis Function) adıyla kullanıldığı da bilinmektedir [13]. Hızlı bir şekilde eğitilebilmeleri, karar verme hızlarının yüksek oluşu ve beyaz kutu (white box) yapısındaki özellikleri ile çalışma sistemlerinin kolay analiz edilebilmesi gibi özelliklerinden ötürü KA'lar diğer öğrencilere göre daha avantajlıdır. Kolektif öğrenme yöntemlerinde de genelde temel öğrenici olarak KA'ların tercih edildiği de bir gerçektir [14]. $\mathrm{Bu}$ nedenle çalışmamızda karar ağaçları her bir alt bölümde kullanılmak üzere tercih edilmiştir. Karar ağac1 algoritmasında, bir ağaç yapısı vardır. Ağacın yaprakları üzerinde sinıflar ve gövdeden yapraklara giden çizgiler üzerinde de işlemeler yer almaktadır. Karar ağacı algoritmasında, ağacın oluşturulması sırasında, üzerinde eğitim yapılan veri seti, özelliklerine göre kümelere bölünür, bu işlem, özyinelemeli bir şekilde (recursion) tekrarlanır ve tekrarlama işlemi önemini yitirene kadar sürer. Yapay öğrenmede karar ağaçları iki şekilde kullanılır. Birincisi sınıflandırma ağaçlarıdır ki sorgu noktasını bir sınıfa yerleştirmeyi amaçlar. İkincisi ise Regresyon Ağaçları (Regression Trees)'dır ve sorgu noktası için bir sınıf yerine sayısal bir değer bulmayı amaçlar.

\subsection{A ğırlıklandırma Yöntemi (Weighting Method)}

Eş. 1'de görüldüğü üzere uzmanların kararları uzaklığa bağlı olarak yapılmaktadır. Burada ağılıklandırma işlemi için kullanılan farklı teknikler vardır: $1 / d, 1 / d^{2}$ ve $1 / d^{3}$. $1 / d^{2}$ li yöntem, $1 / d$ 'ye göre yakındaki öğelerin etkisini çok daha fazla; uzaktakinin etkisini çok daha az almaktadır. $1 / d^{2}$ li geçiş fonksiyonu, yapılan deneysel uygulamalarda diğerlerinden daha başarılı sonuçlar verdiği için tercih edilmiştir.

\subsection{Karmaşılklk Analizi (Complexity Analysis)}

Uzman olarak inşa edilen bir KA'nın büyük O notasyonuna göre zaman karmaşıklığı Eş. 8 ile açıklanmaktadır [15]:

$O(A * n * \log n)$

$n$ örnek sayısını, A ise özellik sayısını göstermektedir. $k$ means kümeleme yönteminin karmaşıklığı ise Eş. 9 ile analiz edilmektedir [16]:

$O(n * k * I * A)$

burada $k$ küme sayısını, $I$ iterasyon sayısını simgelemektedir. Geliştirdiğimiz UK yönteminde $k$ tane KA oluşturmanın maliyeti ise Eş. 10 ile hesaplanmaktadır.

$O\left(k * A * \frac{n}{k} * \log \frac{n}{k}\right)=O\left(A * n * \log \frac{n}{k}\right)$

Bir veri için yalın bir KA inşa etmek ile $k$ tane KA inşa etmek arasındaki zaman karmaşıklığı oranını Eş. 11'de gösterildiği gibi bulunabilir.

$O\left(\frac{A * n * \log n}{A * n * \log \frac{n}{k}}\right)=O\left(\frac{\log n}{\log \frac{n}{k}}\right)$

$k$ parametresi her zaman için küçük bir tamsayı olarak alındığından dolayı önemsenmeyebilir. Bu durumda $k$ tane KA oluşturmak zaman karmaşıklığı açısından maliyetli bir durum olmadığı sonucuna varılabilir. $I$ ve $A$ sayılarının her bir uzman için aynı olduğu düşünülüp sabitlenirse, UK yönteminin karmaşıklığı Eş. 12'de gösterildiği şekle dönüşür.

$O\left(A * n * \log \frac{n}{k}\right)+O(n * k)+O(k)$

Yukarıdaki zaman karmaşıklığı analizinde ilk iki karmaşıklık $k$ tane KA ve $k$ tane küme oluşturmayı göstermektedir. En sonda bulunan $O(k)$ karmaşıklığı ise geçiş fonksiyonuna aittir ve $k$ küçük bir tamsayı olduğu için önemsenmeyecek etki düzeyindedir. 
BA yönteminin karmaşıklık analizi ise [17] Eş. 13'de gösterildiği şekilde olmaktadır.

$O\left(I *\left(A * n+k * n^{2}\right)\right)$

Görüldüğü üzere iterasyon sayıları $(I)$ eşit alınırsa BA'nın karmaşıklığı k-means'e göre oldukça fazladır. Alt bölgelere ayırma işleminin ardından aynı tür sinıflandırıcıların kullanıldığ 1 durumda, alt bölgelere ayırma işleminin etkisi dolayısıyla BA içeren bir yöntemin k-means içeren bir yönteme göre toplam karmaşıklığı fazla olacaktır.

\section{DENEYSEL SONUCCLAR (EXPERIMENTAL RESULTS)}

Uygulama alanı olarak ortak kullanıma açı UCI (University of California Irvine Machine Learning Respository) [18] veri setlerinde 36 tanesi seçilmiştir. Tüm veri setlerine ait değerler normalize edilmiş, kayıp değerler yer değiştirilmiş, nominal değerler ikili sayısal değerlere dönüştürülerek kullanıma hazır hale getirilmiştir. Tüm algoritmalar MATLAB ortaminda, her bir veri seti üzerinde $5 \times 2$ çapraz geçerleme ile test edilmiştir. $5 \times 2$ kat çapraz geçerleme işlemde 2 kat çapraz geçerleme işlemi 5 defa tekrarlanır. 2 kat çapraz geçerleme işleminde ise eğitim seti rastgele 2 parçaya ayrılır. İlk parça eğitim seti ikinci parça test seti olarak belirlenir. Test setindeki örneklerin yüzde kaçının doğru bilindiği eğitim setine danışılarak hesaplanır. İlk işlem tamamlandıktan sonra test seti eğitim setine; eğitim seti test setine dönüştürülerek yüzdelik başarı tekrar hesaplanır. $\mathrm{Bu}$ işlemler 5 defa tekrarlanarak 10 tane yüzdelik başarı sonucu elde edilir. Bu yüzdelik başarıların aritmetik ortalaması çapraz geçerleme işleminin sonucudur. Yapılan uygulamalarda veri setleri $k$-means kümeleme metoduyla (iterasyon sayısı $=100) k$ değerleri sirasıyla 2 ile 50 arasında alınarak kümeleme işlemi yapılmıştır. Veri setlerini daha yüksek sayıda kümelere ayırmak hem hesaplama süresini artırmakta hem de seyrek veri setlerinde çok az elemanlı alt kümeler oluşturmaktadır. Bu durumda $k$-means'teki $k$ parametresi artırıldığında (veri setindeki eleman sayısına yaklaşıldığında) distance weighted $k$-NN sınıflandırmasına benzer bir yapının ortaya çıktığı gözlemlenmiştir. Aynı veri seti üzerinde iki farklı sınıflandırma işlemi tarafından elde edilen sonuçların istatistiksel anlamlılığını belirleyebilmek için T-Test yöntemi kullanılmıştır. T-Test üç farklı değeri sonuç olarak vermektedir: win (başarılı), loss (başarısız) ve tie (eşit). Bu yöntem sayede önerilen yöntemin başarılı olup olmadığı tespit edilebilmektedir. Tablo 1'de 36 UCI veri seti ile yapılan uygulamaların sonuçları görülmektedir. Geliştirdiğimiz UK yöntemi 3 ayrı sınıflandırıcı ile kıyaslanmıştır. Bunlar 1NN (En Yakındaki Komşu algoritmas1), en iyi sonucu veren $k$-NN $(k-E n$ yakın Komşuluk algoritması) ve KA sınıflandırıcılarıdır. T-Test sonucuna göre elde edilen başarı, başarısızlık ve eşitlik sayıları Tablo 1'de gözükmektedir. Görüldüğü üzere UK'nın KA ile kıyaslanmasında 11 adet veri kümesinde performans artışı (win) sağlanmış, 23'ünde değişme olmamış, sadece 2 tanesinde başarısız olunmuştur. Bu da üzerinde çalıșlan yöntemin var olan KA modeline göre daha başarılı sonuçlar elde ettiğini göstermektedir.
Tablo 1. T-Test Sonuçları (T-Test Results)

\begin{tabular}{llll}
\hline T-Test & UK'y1 1NN ile & UK'yı En iyi $k$ - & UK'y1 KA ile \\
Sonucu & Karşılaştırma & $\begin{array}{l}\text { NN ile } \\
\text { Karșlaştırma }\end{array}$ & Karşılaştırma \\
\hline Win & 21 & 11 & 11 \\
Tie & 11 & 18 & 23 \\
Loss & 4 & 7 & 2 \\
\hline
\end{tabular}

Tablo 2'de de görüldüğü üzere T-Test sonucuna göre audiology ve zoo veri setlerinde, elde edilen başarısızlığın nedeni veri setlerinin yoğunluğu ile alakalıdır. $\mathrm{Bu}$ veri kümeleri o kadar küçüktür ki kümelere ayırma işlemi sonucunda oluşan ayrık kümeler içerisinde her bir sınıf etiketini temsil edecek yeteri sayıda örnek bulunmamaktadır. Bu durum oluşturulan alt uzmanların belirli sınıflarda önyargıya sahip olmasına ve doğal olarak genel performansın düşük çıkmasına neden olmaktadır. Tüm veri setleri için oluşturulmuş KA sınıflandırıcısı ile bu uygulamada yaptığımız UK sınıflandırıcısının doğruluk oranları Tablo 2'de verilmektedir. Bu tablo ile tekil bir ögrenci olan KA'nın sınıflandırma performansı ile UK'nın performansı T-Test sonuçlarıyla kıyaslanabilmektedir. İlk sütun tekil KA sınıflandırıcısının veri kümeleri üzerinde verdiği doğruluk değerini; ikinci ve üçüncü sütun ise UK sınıflandırıcısının değerlerini göstermektedir. İkinci sütunda UK için oluşturulan alt küme sayısını yani $k$-means yöntemindeki $k$ parametresini; sonraki sütun UK'nın $k$ değerine bağlık olarak verdiği doğruluk değerini göstermektedir. Son iki sütunda UK ile KA karşılaş̧ırıldığında yüzdelik artış-azalış ile T-Test sonucu verilmektedir. Yaptığımız UK uygulamasında doğruluk oranının bazı veri setlerinde KA doğruluk oranına göre $\% 10,28$ 'e kadar artış sağladığı gözlemlenmiştir. $k$-means ile 36 adet UCI veri seti üzerinde yapılmış olan bu uygulama yumuşak kümelemeli BA algoritmasıyla tasarlanmış UK modeli ile karşılaştııılmak istenmiştir. Fakat deneysel uygulamalar aşamasında BA'lı UK modeli sadece 4 veri seti üzerinde çalışabilmiştir. Bu nedenle önerilen bu model sadece KA sınıflandırıcısı ile karşılaştırılabilmiştir. Kullanıcı tarafindan belirlenen $k$ parametresi ile üzerinde çalışılan veri seti için oluşturulacak alt küme sayısı belirlemektedir. $k$ değeri tarafindan belirlenmektedir ve en uygun değer deneysel sonuçlarla bulunmaktadır. Önerilen bu modelde parametre bağımlılığ olumsuz bir durum olarak algılansa da klasik UK yöntemlerinde de parametre gerekliliğini hatırlatmak isteriz. En uygun $k$ değerinin otomatik olarak bulunmasıyla alakalı olarak değişik çalışmalar yapılmıştır [19, 20]. Ayrıca başka bir çalışmada SOM (Kohonen's Self Organized Map) yönteminden yararlanılarak en uygun $k$ değeri bulunmaya çalışılmıştır [21]. Değişik $\mathrm{k}$ parametreleriyle yapılan deneysel çalışmalarda yoğun bir yapıdaki veri setinin fazla sayıda alt kümelere; seyrek bir yapıdaki veri setinin de az sayıda kümelere bölmenin toplam sınıflandırma başarısını artırdığı gözlemlenmiştir. Burada yoğunluk ölçütü için Eş. 14'te verilen metrik kullanılmıştır.

Yoğunluk $=\frac{N}{A \times C}$ 
Tablo 2. UCI Test Sonuçları (UCI Test Results)

\begin{tabular}{|c|c|c|c|c|c|c|c|c|}
\hline \multirow[t]{2}{*}{ Veri seti Adı } & \multirow[t]{2}{*}{$\begin{array}{l}\text { Örnek } \\
\text { Sayıs1 }\end{array}$} & \multirow[t]{2}{*}{$\begin{array}{l}\text { Sinıf } \\
\text { Sayıs1 }\end{array}$} & \multirow[t]{2}{*}{$\begin{array}{l}\text { Öznitelik } \\
\text { Sayıs1 }\end{array}$} & \multirow{2}{*}{$\begin{array}{l}\text { KA } \\
\text { Doğruluk } \\
\text { Oranı }\end{array}$} & \multicolumn{2}{|l|}{ UK } & \multicolumn{2}{|c|}{$\begin{array}{l}\text { KA ile UK'y1 } \\
\text { karş1laştırma }\end{array}$} \\
\hline & & & & & $k$ & $\begin{array}{l}\text { Doğruluk } \\
\text { Oranı }\end{array}$ & $\begin{array}{l}\text { Yüzdelik } \\
\text { fark }\end{array}$ & $\begin{array}{l}\text { T-Test } \\
\text { Sonucu }\end{array}$ \\
\hline abalone & 4153 & 19 & 10 & 0,2122 & 50 & 0,2231 & 5,11 & win \\
\hline anneal & 890 & 4 & 62 & 0,9883 & 2 & 0,9879 & $-0,05$ & tie \\
\hline audiology & 169 & 5 & 69 & 0,8615 & 2 & 0,8166 & $-5,22$ & loss \\
\hline autos & 202 & 5 & 71 & 0,6614 & 2 & 0,6426 & $-2,84$ & tie \\
\hline balance-scale & 625 & 3 & 4 & 0,7811 & 30 & 0,8614 & 10,28 & win \\
\hline breast-cancer & 286 & 2 & 38 & 0,6692 & 20 & 0,7028 & 5,02 & win \\
\hline breast-w & 699 & 2 & 9 & 0,9465 & 4 & 0,9536 & 0,76 & tie \\
\hline col10 & 2019 & 10 & 7 & 0,7575 & 3 & 0,7559 & $-0,21$ & tie \\
\hline colic & 368 & 2 & 60 & 0,8092 & 2 & 0,8212 & 1,48 & tie \\
\hline credit-a & 690 & 2 & 42 & 0,8197 & 4 & 0,8533 & 4,10 & win \\
\hline credit-g & 1000 & 2 & 59 & 0,6870 & 20 & 0,7140 & 3,93 & win \\
\hline d159 & 7182 & 2 & 32 & 0,9698 & 2 & 0,9610 & $-0,90$ & tie \\
\hline diabetes & 768 & 2 & 8 & 0,7036 & 10 & 0,7375 & 4,81 & win \\
\hline glass & 205 & 5 & 9 & 0,6527 & 5 & 0,6615 & 1,35 & tie \\
\hline heart-statlog & 270 & 2 & 13 & 0,7415 & 35 & 0,8015 & 8,09 & win \\
\hline hepatitis & 155 & 2 & 19 & 0,7923 & 4 & 0,8103 & 2,28 & tie \\
\hline hypothyroid & 3770 & 3 & 31 & 0,9943 & 2 & 0,9932 & $-0,11$ & tie \\
\hline ionosphere & 351 & 2 & 33 & 0,8547 & 35 & 0,8991 & 5,20 & win \\
\hline iris & 150 & 3 & 4 & 0,9333 & 2 & 0,9400 & 0,71 & tie \\
\hline kr-vs-kp & 3196 & 2 & 39 & 0,9901 & 2 & 0,9838 & $-0,63$ & tie \\
\hline labor & 57 & 2 & 26 & 0,8596 & 2 & 0,8526 & $-0,82$ & tie \\
\hline letter & 20000 & 26 & 16 & 0,8234 & 2 & 0,8203 & $-0,38$ & tie \\
\hline lymph & 142 & 2 & 37 & 0,7901 & 3 & 0,7775 & $-1,60$ & tie \\
\hline mushroom & 8124 & 2 & 112 & 1,0000 & 2 & 0,9997 & $-0,03$ & tie \\
\hline primary-tumor & 302 & 11 & 23 & 0,4265 & 2 & 0,4351 & 2,02 & tie \\
\hline ringnorm & 7400 & 2 & 20 & 0,8842 & 10 & 0,9375 & 6,03 & win \\
\hline segment & 2310 & 7 & 18 & 0,9436 & 2 & 0,9474 & 0,39 & tie \\
\hline sick & 3772 & 2 & 31 & 0,9824 & 2 & 0,9846 & 0,22 & tie \\
\hline sonar & 208 & 2 & 60 & 0,7000 & 5 & 0,7231 & 3,30 & tie \\
\hline soybean & 675 & 18 & 83 & 0,8824 & 2 & 0,8809 & $-0,17$ & tie \\
\hline splice & 3190 & 3 & 287 & 0,9254 & 2 & 0,9066 & $-2,03$ & tie \\
\hline vehicle & 846 & 4 & 18 & 0,6849 & 5 & 0,6835 & $-0,21$ & tie \\
\hline vote & 435 & 2 & 16 & 0,9361 & 3 & 0,9549 & 2,01 & tie \\
\hline vowel & 990 & 11 & 11 & 0,6873 & 9 & 0,7143 & 3,94 & win \\
\hline waveform & 5000 & 3 & 40 & 0,7394 & 35 & 0,8051 & 8,89 & win \\
\hline zoo & 84 & 4 & 16 & 0,9762 & 2 & 0,9214 & $-5,61$ & loss \\
\hline
\end{tabular}

Tablo 3. Yoğun ve Seyrek veri setleri (Dense and Sparce Datasets)

\begin{tabular}{llllllll}
\hline & & & & & \multicolumn{3}{c}{ Yüzdelik Değişiklik } \\
& $N$ & $C$ & $A$ & Yoğunluk & $k=5$ & $k=10$ & $k=20$ \\
\hline balance-scale & 625 & 3 & 4 & 52,1 & 3,77 & 5,29 & 5,53 \\
breast-w & 699 & 2 & 9 & 38,8 & 1,36 & 1,33 & 1,48 \\
waveform & 5000 & 3 & 40 & 41,7 & 0,44 & 3,24 & 6,31 \\
autos & 202 & 5 & 71 & 0,2 & $-11,68$ & $-21,11$ & $-30,84$ \\
colic & 368 & 2 & 60 & 0 & $-0,53$ & $-5,17$ & $-9,53$ \\
labor & 57 & 2 & 26 & 0,5 & $-11,42$ & $-11,83$ & $-9,38$ \\
\hline
\end{tabular}

$N, A$ ve $C$ değerleri sırasıyla veri setindeki örnek sayısı, öznitelik sayısı ve sınıf sayısıdır. Tablo 3'de ilk 3 verinin yoğunluğu olukça fazla, son üç veri setinin de yoğunluğu oldukça azdır. $k=3$ alındığında elde edilen doğruluk başarı değerlerine göre $k$ 'nın 5,10 ve 20 alındığında elde edilen başarı değerleri arasında bir karşılaştırma yapılmıştır. Görüldüğü üzere yoğun veri setlerde $k$ değerinin artmasıyla daha yükssek başarı, azalmasıyla da daha düşük başarılar elde edilmiştir. Ayrıca KA ve UK sinıflandırıcı sistemlerinde oluşturulan karar ağaçlarının içyapılarındaki 
düğüm sayıları da ayrı bir karmaşıklık ölçütü olabilir. Bu nedenle KA ve UK sınıflandırıcılarının içerisinde bulunan düğüm sayıları Tablo 4'de verilmiştir. UK'da $k$ değeri 5 alındığında karar ağaçlarında oluşan toplam düğüm sayısı 8662, KA'lardaki toplam düğüm sayıları ise 7368 'dir. Birbirine çok yakın olan bu değerler önerilen yöntem ile var olan KA yönteminin karmaşıklık açısından birbirine benzediğini göstermektedir.

Tablo 4. KA ve UK' daki düğüm sayıları (Number of nodes in DT and MoE)

\begin{tabular}{|c|c|c|}
\hline Veriseti & KA düğüm sayısı & UK düğüm sayısı \\
\hline abalone & 1515 & 1502 \\
\hline anneal & 21 & 34 \\
\hline audiology & 37 & 42 \\
\hline autos & 51 & 58 \\
\hline balance-scale & 69 & 74 \\
\hline breast-cancer & 63 & 58 \\
\hline breast-w & 37 & 22 \\
\hline $\operatorname{col} 10$ & 295 & 396 \\
\hline colic & 47 & 50 \\
\hline credit-a & 93 & 106 \\
\hline credit-g & 209 & 198 \\
\hline d159 & 205 & 462 \\
\hline lymph & 21 & 28 \\
\hline mushroom & 27 & 48 \\
\hline diabetes & 139 & 138 \\
\hline glass & 47 & 66 \\
\hline heart-statlog & 35 & 66 \\
\hline hepatitis & 19 & 30 \\
\hline primary-tumor & 81 & 70 \\
\hline ringnorm & 531 & 600 \\
\hline segment & 91 & 130 \\
\hline sick & 53 & 76 \\
\hline sonar & 35 & 44 \\
\hline soybean & 81 & 120 \\
\hline splice & 167 & 220 \\
\hline vehicle & 151 & 170 \\
\hline vote & 19 & 26 \\
\hline vowel & 191 & 240 \\
\hline waveform & 737 & 620 \\
\hline zoo & 7 & 10 \\
\hline hypothyroid & 23 & 78 \\
\hline ionosphere & 37 & 46 \\
\hline iris & 9 & 20 \\
\hline kr-vs-kp & 73 & 202 \\
\hline labor & 9 & 12 \\
\hline letter & 2413 & 2600 \\
\hline TOPLAM & 7638 & 8662 \\
\hline
\end{tabular}

\section{SONUÇLAR VE TARTIŞMALAR (RESULTS AND DISCUSSIONS)}

$\mathrm{Bu}$ çalışmada denetimsiz öğrenme ile veri seti kümelere bölünmüş ve denetimli bir öğrenme gerçekleştirilmiştir. Bu durum önerilen yönteme ait hesaplama süresinin tekil öğrenicilere göre artırmasını sağlamıştır. $k$-means ile yapılan kümeleme işleminde her defasında başka küme grupları oluştuğu için sınıflandırma başarısı kümelerin yerleşimine, eleman sayısına ve yapısına bağlı olarak az da olsa değişiklik göstermektedir. Fakat yapılan T-Test analizlerinde hemen hemen aynı sayıda elde edilen win, tie, loss çıktılarından dolayı bu değişiklik önemsenmeyecek düzeydedir. Ayrıca $k$-means metodu iki boyutlu veri kümelerinde dairesel; üç boyutlu ortamda da küresel tarzda kümeleme yapmaktadır. Bu nedenle oluşan alt kümelerdeki örnekler o kümenin merkez noktası etrafında saçılmış bir şekilde bulunmaktadır. Kısaca $k$-means metodunda oluşturulan kümeler iç içe veya sarmal yapıda olmamaktadır. Bu özellik, UK'da uzaklığa bağlı olarak ağırlıklandırma ile sınıflandırma yapan geçiş fonksiyonu için çok uygun olmaktadır ve yüksek başarı elde edilmesini sağlamaktadır. Her ne kadar literatürde [20] BA algoritmasının uzaklık tabanlı $k$-means tarzı algoritmalara göre daha iyi bir kümeleme yaptığı belirtilse de, kovaryans matrisinin her veri seti için oluşturulamaması önemli bir dezavantaj olduğu kabul edilmektedir. $\mathrm{Bu}$ durumda kmeans metodunun her veri setine için uygulanabilir olması büyük bir avantaj olarak karşımıza çıkmaktadır. Her hangi bir test noktası, ait olduğu alt kümenin sınırına (class boundary) ya da karar sınırına (decision boundary) çok yakın bir yerde ise sınıflandırma işleminin nasıl gerçekleşeceği konusu çalışmamızın başında merak edilmiş; bu durumda hangi alt kümenin uzmanı ile etiketleneceği sorusu cevaplanmak istenmişti. Uzaklığa bağlı olarak sınıflandırma yapan geçiş fonksiyonu sayesinde bu sorun ortadan kaldırılmıştır. Sınıflandırma işleminde eğitim setindeki tüm uzmanlara yer verilmiştir. Fakat diğer uzmanlara göre test noktasından daha uzakta bulunan uzmanların etkisi $1 / \mathrm{d}^{2}$ den dolayı çok az olmaktadir. Uzaktaki uzmanların mevcut test noktası hakkındaki kararlarının belirlenmesi ve kararlarının geçiş fonksiyonunda hesaplamaya dâhil edilmesi hesaplama süresini artırmaktadır. $\mathrm{Bu}$ durumda sadece test noktasının çevresinde ve yakınında bulunan uzmanları sınıflandırma işlemine almak için otomatize edilmiş bir sistem üzerinde çalışma yapılabilir. Ayrıca bu sınıflandırma mekanizmada $k$ parametresi kullanıcıdan istenmektedir. Parametrenin kullanıcı tarafından belirlemesi olumsuz bir durum olarak algılansa da diğer birçok sınıflandırma ve kümeleme yönteminin parametreye dayalı çalıştığını unutmamak gerekir. Elbette ki denetimli ve denetimsiz öğrenme yöntemleri için en uygun parametrenin seçimine yönelik birçok bilimsel çalışma vardır. $\mathrm{Bu}$ çalışmalardan da yararlanılarak performans artırımı sağlanabilir. abalone, waveform ve ringnorm gibi bazı UCI veri setlerinde uzman sayısı artırıldıkça genel sınıflandırma başarısının da arttığ1 gözlemlenmiştir. $\mathrm{Bu}$ durumun bazı dezavantajları vardır. Öncelikle hesaplama süresi bir miktar artmaktadır. Ayni zamanda uzman sayısının artırılması alt kümeler içerisinde kalan eleman sayısının azalması anlamına gelmektedir. $\mathrm{Bu}$ durum alt kümelerin saflaşmasına, üzerinde çalıştı̆̆ımız yöntemin $k$-NN sinıflandırıcısına benzer bir yapıya dönüşmesine sebep olmaktadır. Diğer bir deyişle $k$ means'teki $k$ parametresi eleman sayısına yani $N$ 'e yaklaştıkça sınıflandırma işlemi $1 / \mathrm{d}^{2}$-distance-weightedkNN ile yapılmış gibi olacaktır. Bu durum da hesaplama süresinin fazla olmaması ve $k$-NN benzeri bir 
sınıflandırıcının oluşmaması için k değeri N'den oldukça küçük seçilmelidir. Veri seti, $k$ adet kümeye bölündüğünde bazı alt kümelerdeki örnek sayısının azaldığını ve bu şekilde alt kümelerin saflaştığı yani tek sınıf türünden örnekler içerdiği gözlemlenmiştir. Bu durum, alt kümenin belirli bir sınıf hakkında önyargılı (bias) karar vermesine sebep olmuştur. Bu durumun denetimli öğrenmede olumsuz bir durum olarak tanımlansa da bu çalışmada performans artırımı için olumlu bir faktör olmuştur. Yapılan uygulamalarda, balance-scale, heart-statlog ve waveform gibi bazı veri setlerinde oluşturulan her bir alt bölgenin yoğun olduğu ve aynı veri setindeki diğer alt bölgelerden doğrusal karar çizgileriyle ayrıldığı gözlemlenmiştir. Bu tür veri setlerde yüksek başarı elde edilmiştir. Üzerinde uygulama yapılan diğer veri setlerde geliştirilen bu yöntemin neden başarılı ya da başarısız olduğu üzerinde çalışmalar yapılabilir. Bu amaçla bir veri setinin istatistiksel özelliklerinin yanı sıra geometrik meta öznitelikleri [22] de ele alınarak Meta Öğrenme ile başarının ya da başarısızlığın nedenleri incelenebilir. Veri setlerine ait meta özellik çıkarımı ile alakalı yapılan bazı çalışmalar vardır [23] ve bu çalışmalarda hangi özelliklerin sınıflandırma başarısına etki ettiği incelenmiştir. Ayrıca iki boyutlu daha çok yapay veri seti üretilerek hangi veri setlerinde geliştirilen yöntemin daha iyi çalıştığı Kovaryans Matrisi yardımıyla da anlaşılmaya çalışılabilir. İleri aşamalarda, uzman olarak KA'nın haricinde farklı sınıflandırıcılar ve farklı kümeleme yöntemleri de kullanılarak performans karşılaştırmaları yapılabilir. Ayrıca BA ile yapılan UK çalışmaları ile üzerinde çalıştığımız yöntem değişik açılardan kıyaslanabilir.

\section{SONUÇLAR (CONCLUSIONS)}

Bir veri setinin bazı bölgelerinin diğerlerinden farklı özelliklere sahip olması genel sınıflandırma performansını düşürebilir. $\mathrm{Bu}$ nedenle bu bölgeleri diğerlerinden ayırmak gerekebilir ve bu bölgeler için özel çözümlerin sunulması zorunlu olabilir. Bu amaçla veri setinde önce kümeleme yapılmış, sonra her bir bölge için ayrı bir uzman eğitilmiş, ardından bu uzmanlar bir geçiş fonksiyonuyla birleştirilerek uzman karışımı bir sistem elde edilmiştir. Bu çalışmamızda tüm veriye tek bir model belirlemek yerine, veriyi alt bölgelere ayırıp her biri için farkı modeller belirlemenin sınıflandırma performansını genel olarak artırmaktadır. Geleneksel yumuşak kümelemeli UK modelinden farklı olarak sunduğumuz bu çalışma, tüm veri setlerine uygulanabilmesi açısından oldukça avantajlı bir durumdadir.

\section{KAYNAKLAR (REFERENCES)}

1. Jacobs R, Jordan M, Nowlan J, Hinton G.E., Adaptive mixtures of local experts Neural Computer, 3 (1), 7987, 1991.

2. Alpaydin E, Mixture of Experts, Introduction to Machine Learning E-Book, MIT Press, A.B.D., 301$305,2014$.
3. Yuksel E., Twenty Years of Mixture of Experts, IEEE Transactions On Neural Networks And Learning Systems, 23 (8), 1177-1193, 2012.

4. Akben S.B., Alkan A., Density-Based Feature Extraction to Improve the Classification Performance in the Datasets Having Low Correlation Between Attributes, Journal of the Faculty of Engineering and Architecture of Gazi University, 30 (4), 597-603, 2015.

5. Dempster A.P., Laird N.M., Rubin D.B,. Maximum Likelihood from Incomplete Data viathe EM Algorithm. Journal of the Royal Statistical Society, Series B (39), 1-38, 1977.

6. Chamroukhi, F., Non-Normal Mixtures of Experts, arXiv preprint arXiv:1506.06707, Fransa, 1-61, 2015.

7. Bulut F., Amasyalı M.F., Sönmez A.C., Uzman Karışımlarında Yeni Bir Yaklaşım: Uzman Kararlarının Yeni Bir Geçiş Fonksiyonuyla Birleştirmesi, Akıllı Sistemlerde Yenilikler ve Uygulamaları, ASYU-INISTA 2014, İzmir, 62-66, 2014.

8. Nguyen H.D., McLachlan G.J., Laplace mixture of linear experts, Computational Statistics \& Data Analysis, 93 (1), 177-191, 2016.

9. Shepard D., A Two-dimensional interpolation function for irregularly spaced data, Proceedings of the 23rd National Conference of the ACM, A.B.D., 517-523, 1968.

10. Bulut F., Bucak İ.Ö., An urgent precaution system to detect students at risk of substance abuse through classification algorithms, Turkish Journal of Electrical Engineering \& Computer Sciences, 22 (3), 690-707, 2014.

11. Jordan M.I., Jacobs R.A., Hierarchical Mixture of Experts and the EM Algorithm, Journal Neural Computation archive, 6 (2), 181-214, 1994.

12. Xu L., RBF nets, Mixture Experts and Bayesian YingYang Learning, Elsevier Neurocomputing 19, 223-257, 1998.

13. Kubat M., Decision Trees Can Initialize Radial-Basis Function Networks, IEEE Transaction On Neural Networks, 9 (5), 813-821, 1998.

14. Zhou Z.H., Ensemble Methods: Foundations and Algorithms, CRC Press, A.B.D., 270-272, 2012.

15. Witten I.H., Frank E., Data Mining: Practical Machine Learning Tools and Techniques, $3^{\text {rd }}$ Edition, Elsevier, 196-198, 2011.

16. Myatt G.J, Making Sence of Data: A Practical Guide to Exploratory Data Analysis and Data Mining, Wiley, A.B.D., 120-129, 2007.

17. Moore E.J., Bourlai T., Expectation Maximization of Frequent Patterns, a Specific, Local, Pattern-Based Biclustering Algorithm for Biological Datasets, IEEE/ACM Transactions on Computational Biology and Bioinformatics, 13 (5), 812-824, 2016.

18. Bache K., Lichman M., UCI Machine Learning Repository, URL: http://archive.ics.uci.edu/mlIrvine, CA: University of California, School of Information and Computer Science, 2014. 
19. Özturk C., Hancer E., Karaboga D., Automatic Clustering With Global Best Artificial Bee Colony Algorithm, 29 (4), 677-687, 2014.

20. Bayá A.E., Granitto P.M., How Many Clusters: A Validation Index for Arbitrary-Shaped Clusters in IEEE/ACM Transactions on Computational Biology and Bioinformatics, 10 (2), 401-414, 2013.

21. Hsu C.C., Lin S.H., Visualized Analysis of Mixed Numeric and Categorical Data Via Extended Self-
Organizing Map in IEEE Transactions on Neural Networks and Learning Systems, 23 (1), 72-86, 2012.

22. Ho T.K., \& Basu M., Complexity Measures of Supervised Classification Problems, IEEE Transaction on Pattern Analysis and Machine Intelligence, 24 (3), 289-300, 2002.

23. Basu M., Data Complexity in Pattern Recognition, Springer Science \& Business Media, Londra, İngiltere, 2010. 
